Abstracta Iranica Abstracta Iranica

Revue bibliographique pour le domaine irano-aryen

Volume 27 | 2006

Comptes rendus des publications de 2004

\title{
Islom - nurbakhshi adabiiot va farhang. Douchanbe, Nashriioti «Sino », 2004, 214 p., ill. [L'islam : phare des lettres et de la culture]
}

\section{Stéphane A. Dudoignon}

\section{(2) OpenEdition}

1 Journals

\section{Édition électronique}

URL : http://journals.openedition.org/abstractairanica/6200

DOI : 10.4000/abstractairanica.6200

ISSN : 1961-960X

Éditeur :

CNRS (UMR 7528 Mondes iraniens et indiens), Éditions de l'IFRI

\section{Édition imprimée}

Date de publication : 15 mai 2006

ISSN : 0240-8910

Référence électronique

Stéphane A. Dudoignon, «Islom - nurbakhshi adabiiot va farhang. Douchanbe, Nashriioti « Sino », 2004, 214 p., ill. [L'islam : phare des lettres et de la culture] », Abstracta Iranica [En ligne], Volume 27 | 2006, document 262, mis en ligne le 02 janvier 2007, consulté le 25 septembre 2020. URL : http://

journals.openedition.org/abstractairanica/6200; DOI : https://doi.org/10.4000/abstractairanica.6200

Ce document a été généré automatiquement le 25 septembre 2020.

Tous droits réservés 


\title{
Islom - nurbakhshi adabiiot va farhang. Douchanbe, Nashriioti « Sino ", 2004, 214 p., ill. [L'islam : phare des lettres et de la culture]
}

\author{
Stéphane A. Dudoignon
}

Un philologue de l'Université de Douchanbe auquel on doit une édition récente, en caractères cyrilliques, des œuvres du religieux et mystique de Kulab Sāmi` Ādīna-Zāda «Khatlānī » (1907[?]-95) - cf. Daftari sabz [Le cahier vert], Douchanbe, Nashriioti "Sino ", 2004, voir c.r. $n^{\circ} 331-$, se penche ici sur divers aspects de la culture islamique dans la littérature et les sociabilités savantes tadjiques $\mathrm{du} 20^{\mathrm{e}} \mathrm{s}$. Avec autant de zèle que les plumitifs de l'histoire officielle en mettaient naguère à mettre en lumière le caractère socialiste de cette littérature et de ses sociabilités, l'A. s'attache à en révéler le caractère foncièrement islamique. Pour ce faire, un premier et important chapitre (pp. 21-133) est consacré aux différentes versions élaborées au cours du $20^{\mathrm{e}} \mathrm{s}$. du manuel de religion et d'éthique Zarūriyāt-i dinniya [Les obligations religieuses], en partant de la version du polygraphe réformiste de Boukhara 'Aynī (1915) pour arriver à celle d'A. Dhākirī (2000), en passant par le manuel homonyme de Mullā 'Abd-Allàh-i Khurdī (1958-92), figure importante du mouvement du Renouveau Islamique dans la région de Qurghan-Teppa pendant la dernière décennie d'histoire de l'URSS. (Il faut cependant noter, ce que l'A. ne fait pas, que cette version de Mullā 'Abd-Allàh-i Khurdī a connu deux variantes successives, sensiblement différentes l'une de l'autre, dont une cosignée par Mullā Rādiq, autre figure du RI dans le sud-ouest du Tadjikistan.) A signaler également, un sous-chapitre (pp. 160 sqsq.) sur le Mawlūd-i sharîf yākhūd Mir'āt-i khayr albashar (1331/1912) d'un autre polygraphe réformiste et activiste politique de Boukhara, 'Abd al-Ra'uf Fitrat (1884-1938) - l'A. s'attardant sur le contexte historique, les spécificités formelles et l'arrière-plan théologique de cette œuvre. Derrière le paravent d'une prose aussi verbeuse que celle, soviétique, dont il cherche à prendre le contrepied, Mahmadaminov fournit nombre de données historiques, encore pour la plupart très incomplètes et faiblement documentées, ainsi que quelques témoignages précieux 
sur l'ambiance dans le souterrain islamique du Tadjikistan méridional dans les années 1960 à 1980 - voir notamment ses paragraphes (pp. 157 sqsq.) sur les conséquences qu'a eues au début de la période Brejnev, pour certains apparatchiks de la région de Kulab, leur participation aux monumentales funérailles du shaykh naqshbandī Pīr-Muhammad «Sang-i Kulūla » (1882-1968). Regrettons que le manque de familiarité évident de l'A. avec une certaine clandestinité de la période soviétique limite grandement sa contribution à l'histoire contemporaine de l'islam tadjik, le confinant à une énième réhabilitation des mouvements de réforme islamique dans l'émirat de Boukhara à la fin de la période coloniale.

INDEX

Thèmes : 7. Islam

\section{AUTEURS}

STÉPHANE A. DUDOIGNON

CNRS - Paris 